\title{
PERFORMANCE OF CONDITIONAL MODELS IN GOLD RISK MANAGEMENT
}

\author{
Sergio Guilherme Schlender \\ sergio.schlender1@gmail.com \\ Marcelo Brutti Righi \\ marcelobrutti@hotmail.com \\ Paulo Sergio Ceretta \\ ceretta10@gmail.com
}

Universidade Federal de Santa Maria - Santa Maria, RS / Brasil

http://dx.doi.org/10.1590/1413-2311.0022015.54927

Recebido em 06/02/2015

Aprovado em 21/12/2015

Disponibilizado em 31/12/2015

Avaliado pelo sistema "double blind review"

Revista Eletrônica de Administração

Editor: Luís Felipe Nascimento

ISSN 1413-2311 (versão "on line")

Editada pela Escola de Administração da Universidade Federal do Rio Grande do Sul.

Periodicidade: Quadrimestral

Sistema requerido: Adobe Acrobat Reader

\begin{abstract}
Even with studies to confront different risk models for gold, there is no consensus about what is the best approach or models when considering the presence of extreme negative values. To that, we employ a backtesting in conditional models with distinct distributions in order to estimate VaR and ES risk measures and, thus, find a pattern for the risk of investments in gold. We verify that the EVT approach has more conservative and volatile risk estimates, with satisfactory results in extreme situations.
\end{abstract}

Keywords: Gold; Risk measures; Risk models.

\section{DESEMPENHO DE MODELOS CONDICIONAIS NA GESTÃO DE RISCO DO OURO}

\section{RESUMO}

Mesmo com estudos que comparam diferentes modelos de risco para o ouro, não há consenso sobre qual é a melhor abordagem ou modelo quando se considera a presença de valores negativos extremos. Para isso, emprega-se um backtesting em modelos condicionais com distribuições distintas, a fim de estimar as medidas de risco VaR e ES, e, assim, encontrar um padrão para o risco dos investimentos no ouro. Verificamos que a abordagem EVT tem 
estimativas de risco mais conservadora e volátil, com resultados satisfatórios em situações extremas.

Palavras-Chave: Ouro; Medidas de Risco; Modelos de Risco.

\title{
RENDIMIENTO DE MODELOS CONDICIONALES EN LA GESTIÓN DEL RIESGO DEL ORO
}

\begin{abstract}
RESUMEN
Incluso con los estudos que comparan diferentes modelos de riesgo para el oro, no hay consenso en lo que es el mejor enfoque o modelo cuándo se considera la presencia de valores negativos extremos. Para esto, se emplea un backtesting en modelos condicionales con distribuciones distintas, a fin de estimar las medidas de riesgo VaR y ES, y, así, encontrar un padrão para el riesgo de las inversiones en el ouro. Encontramos que el enfoque EVT hay estimaciones de riesgo más conservadora y volátil, con resultados satisfactorios en situaciones extremas.
\end{abstract}

Palabras Clave: Oro; Medidas de Riesgo; Modelos de Riesgo.

\section{INTRODUCTION}

In the expectation of one stabilizer force against extreme negative market shocks, gold has always been well regarded for risk protection by investors, especially for applications in allocation portfolio and hedging against financial risk. The main reason for this tendency is the good results against macroeconomic fluctuations, such as exchange, inflation and geopolitical events. However, these results do not observe the greater detachment of gold with the economic variables and its wider use as an investment instrument, as well as the low performance of gold in the protection of negative economic conditions, which have instigated questions about its behavior in scratch protection.

Regarding the role of gold in risk management, volatility is traditionally considered a risk measure. Despite being more persistent and less sensitive to leverage effects than other metals, it presents a variable pattern over time as well as "flight to safety syndrome" in its demand during turbulent periods (Hammoudeh and Yuan, 2008; Hammoudeh et al., 2011). Thus, gold denotes more attention for some peculiarities, such as asymmetric distribution and influence of extreme events. Chkili et al. (2014) suggest the use of models that promote more attention for asymmetry in gold distribution. However, So et al. (2014) state that the asymmetry can lead to biased risk estimations, due to the modeling of tail asymmetry, not finding a suitable return distribution that can describe well the tail parts of the true gold distribution. Moreover, recent evidence of falls in gold prices (see Figure 1) shows a lack of REAd | Porto Alegre - Edição 82 - No 3 - setembro/dezembro 2015 - p. 648-658 
persistence and increased sensitivity of volatility for tail distribution values, especially for extreme negative events, and denotes relevant attention for gold risk estimation. Thus, the question raised is: how to resolve this misunderstanding and find one risk model for gold investments?

To answer this question, recent advances on the regulation and definition of capital requirements have considered the potential loss of future earnings through tail risk measures or quantile basis, such as the Value at Risk (VaR) and Expected Shortfall (ES). VaR is the maximum loss given a confidence level during a certain period, while ES is the average loss once this loss overcomes VaR. For risk management of gold investments, Jang (2007) apply the extreme value distribution (EVT) for the analysis of VaR and ES in daily returns of the London Gold Market over the period of January 1, 1985 through March 31, 2006 and presents a better choice than the estimates of Normal GARCH distribution, commonly applied in the analysis of gold volatility. Hammoudeh et al. (2011) explore the implications of different precious metals in risk management models, such as RiskMetrics and GARCH in daily returns of COMEX market during the period of January 4, 1995 to November 12, 2009, but do not reveal specific results for the performance of risk in gold investments. Finally, Chaithep (2012) conducts an analysis of the VaR with EVT in U.S. daily gold price over the period of January 1, 1985 to August 31, 2011, and finds that EVT shows better performance in comparison to Historical Simulation and Variance-Covariance model.

Even with the existence of studies to confront different risk models for gold, there is no consensus about what is the best approach or even a performance rank of these models in extreme situations. It is exactly this gap we intend to fill, by providing a detailed assessment of risks in gold investments that allow inferring which model is more precise in a backtesting framework, especially considering the period of fall in gold prices. To that, we consider the estimation of VaR and ES from COMEX future gold log-returns through conditional models with distinct distributions, regarding the estimation window and significance level dimensions, during the period of January 2007 to December 2013.

\section{MATERIAL AND METHODS}

We utilize daily data from the Commodity Exchange, Inc. (COMEX) future gold price of the most negotiated future contract of gold (GC2). The sample of log-returns is from January 2007 to December 2013, totalizing 1753 observations. In view of protection against

REAd | Porto Alegre - Edição 82 - N 3 - setembro/dezembro 2015 - p. 648-658 
negative extreme impacts in the market, the sample contains both the sub-prime and the Eurozone crises, resenting a good challenge to the adaptation of estimation models. Since the risk in gold investments is regarding changes in its values, we consider the usual log-returns for our analysis.

We now explain the risk measures and models present in this paper. Consider the stationary random change in gold price as $X_{T}$, which have a fully parametric location-scale specification based on expectation, dispersion and random component, as $X_{T}=\mu_{T}+\sigma_{T} z_{T}$, where, for period $T \mu_{T}$ is the conditional mean (location), $\sigma_{T}$ is the conditional standard deviation (scale) and $z_{T}$ represents a zero location and unit scale innovations of white noise series, which can assume many probability distribution functions $F$. Based on this framework, we now define $\mathrm{VaR}$ and ES. To that, given a value $\alpha \in(0,1)$, the $\mathrm{VaR}$ at a significance level $\alpha$ is the quantile $q_{\alpha}$ of $X_{T}$ for this level. Mathematically, VaR is defined as (1).

$$
\begin{aligned}
\operatorname{VaR}_{T}^{\alpha} & =q_{\alpha}\left(X_{T}\right) \\
& =q_{\alpha}\left(\mu_{T}+\sigma_{T} z_{T}\right) \\
& =\mu_{T}+\sigma_{T} q_{\alpha}\left(z_{T}\right) \\
& =\mu_{T}+\sigma_{T} F^{-1}(\alpha) .
\end{aligned}
$$

Based on this definition we can note that VaR does not consider information after the quantile of interest, only the point itself. ES can outperform this drawback. Thus, ES at significance level $\alpha$ is the expectation of $X_{T}$, once $X_{T}$ is below VaR for this level, i.e., an extreme loss. Formally, formulation (2) defines ES.

$$
\begin{aligned}
E S_{T}^{\alpha} & =E\left[X_{T} \mid X_{T}<\operatorname{VaR}_{T}^{\alpha}=q_{\alpha}(X)\right] \\
& =E\left[\mu_{T}+\sigma_{T} z_{T} \mid \mu_{T}+\sigma_{T} z_{T}<\mu_{T}+\sigma_{T} F^{-1}(\alpha)\right] \\
& =\mu_{T}+\sigma_{T}\left(\alpha^{-1} \int_{0}^{\alpha} q_{s}\left(z_{T}\right) \mathrm{d} s\right) .
\end{aligned}
$$

For the filtering, we estimate an AR (1)-GARCH $(1,1)$ model with parameters estimated through Quasi-Maximum Likelihood. We consider other GARCH specifications, as well lag numbers, however they do not change our results qualitatively. Thus, we keep the most simple and parsimonious model. Due to lack of space we do not present estimation results here, but they are available upon request. We consider four candidates for the distribution $F$ : i) The Normal or Gaussian, which serves as a benchmarking; ii) the Skewed

REAd | Porto Alegre - Edição 82 - Nº 3 - setembro/dezembro 2015 - p. 648-658 
Student's $t$, in order to incorporate the asymmetric leptokurtic behavior of financial data; iii) the empirical one, which turns out to the Filtered Historical Simulation (FHS) method (Barone-Adesi et al.,1999; Giannopoulos and Tunaru, 2005), allowing more flexibility; and the Generalized Pareto Distribution (GPD) that is based on the Extreme Value Theory (EVT), see McNeil and Frey (2000) for details.

We consider an estimation window of 500 observations, i.e., for each day from the observation 501 to the end of the sample), VaR and ES are estimated using the last 500 observations, for the four models we are considering. Other estimation windows were also used, but the results do not change qualitatively. For brevity, we keep the results for the window that has the best overall results. We study $1 \%$ and $5 \%$ significance levels for the quantiles. We compute the violation rate (a violation means that the return obtained in a determined day was below than forecasted $\mathrm{VaR}$ ), mean, standard deviation, skewness and kurtosis for VaR and ES estimates. We also consider backtesting procedures, using the Christoffersen (1998) test for VaR (null hypothesis of correct proportion and independence of violations) and McNeil and Frey (2000) for ES (null hypothesis that the mean of differences between violations and forecasted ES is zero).

\section{RESULTS}

We provide a visual insight about the pattern of prices and log-returns of gold through Figure 1 and Figure 2, which exhibit a plot of the daily future gold prices of COMEX from January 1975 to December 2013, and it shows log-returns for the data used, respectively. Further, we offer numerical information through some descriptive statistics of log-returns in Table 1.

Table 1 - Descriptive statistics of the future gold log-returns from January 2007 to December 2013.

\begin{tabular}{lc}
\hline \multicolumn{1}{c}{ Statistic } & Future gold \\
\hline Minimum & -0.0981 \\
\hline Maximum & 0.0859 \\
\hline Mean & 0.0004 \\
\hline Standard Deviation & 0.0138 \\
\hline Skewness & -0.3346 \\
\hline Kurtosis & Source: Authors \\
\hline \multicolumn{2}{c}{} \\
\end{tabular}


Sergio Guilherme Schlender, Marcelo Brutti Righi \& Paulo Sergio Ceretta

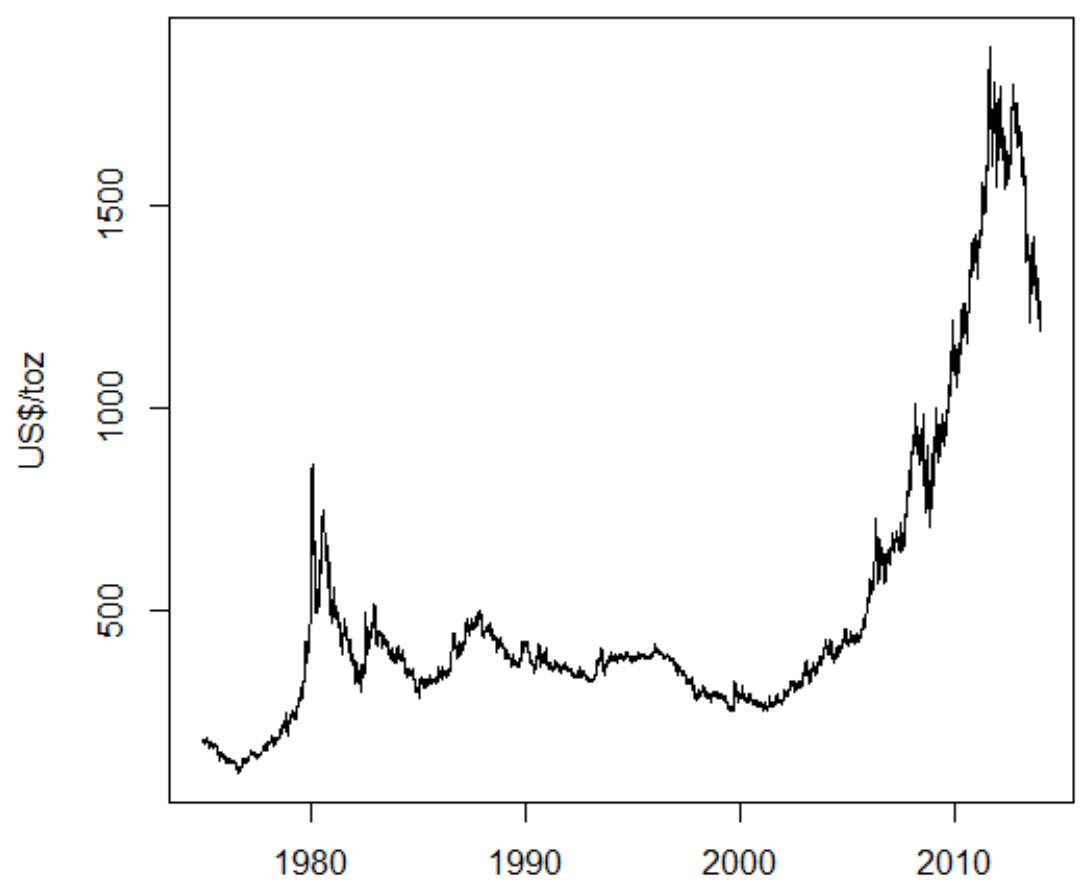

Figure 1 - Prices of the daily COMEX Future gold from January 1975 to December 2013 Source: Authors

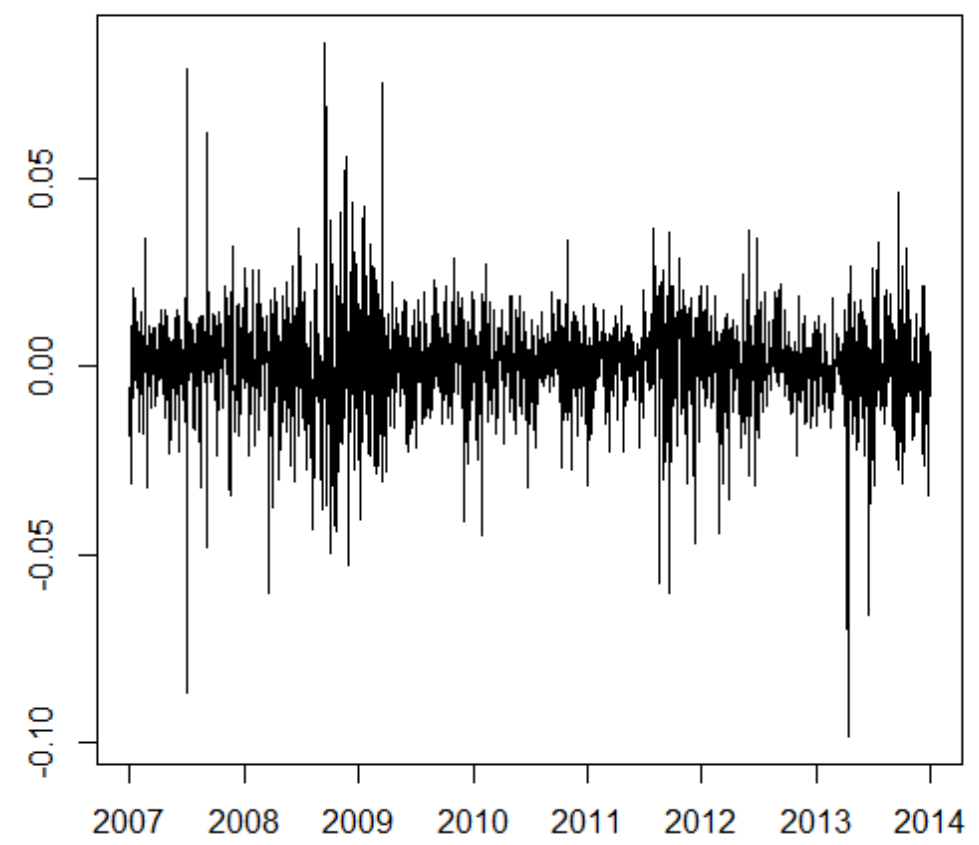

Figure 2 - Log-returns of the daily COMEX Future gold from January 2007 to December 2013 Source: Authors 
Figure 1 denotes the pattern of persistence and low sensitivity of gold prices from extreme events in the period preceding sub-prime crises. However, there are some rise and fall in gold prices in the decades between the years of 1970 to 1990, due to geopolitical events as the Middle East crisis in 1980. Nonetheless, there is a strong increase in gold prices from 2000 until 2008 sub-prime crises. This increase may be related to changes in the gold market with the collapse of Bretton Woods system and to the transition to floating exchange rate regimes (Hillier et al., 2006), where the use of gold as an investment instrument increased (Batten et al., 2010). Chaithep (2012) analyzes this increase with S\&P500 index and verify that the return rate of gold is greater than the index return, which favors the wider use of gold against financial risk. However, there are volatile patterns in a period posterior to the beginning of the crisis in the second half of 2008, with strong rise and fall behavior in future gold prices. The rise of gold prices represent a response of protection against financial market risk. However, the recent fall of gold since 2011/2012, which coincided with Eurozone crisis period, confirms the lack of persistence of this patter and the presence of more negative extreme values, which can difficult gold protection. The possible "flight to safety syndrome" of gold demand during turbulent periods is not confirmed here and we suggest this for future studies. Figure 2 confirms strong oscillations in volatility clusters since sub-prime crisis and confirms this recent instability in gold protection, especially for negative returns. In Table 1, maximum and minimum values point out that the value changed more than $200 \%$ in some days and confirm the period of strong oscillation of gold returns as well as positive impacts in the standard deviation and kurtosis. The leptokurtic behavior and negative skewness denote the impact of large negative values in gold returns and confirm that recent events have increased the proportion of returns for the negative tail of the distribution. Despite this pattern in kurtosis and the skewness, the returns are very close to the unconditional mean.

Table 2 - Risk measure estimation results of the future gold log-returns from January 2007 to December 2013.

\begin{tabular}{|c|c|c|c|c|c|c|c|c|}
\hline $\operatorname{VaR}$ & \multicolumn{4}{|c|}{$1 \%$ significance level } & \multicolumn{4}{|c|}{$5 \%$ significance level } \\
\hline Model & Normal & Skewed $t$ & FHS & EVT & Normal & Skewed $t$ & FHS & EVT \\
\hline Proportion & 0.019 & 0.015 & 0.014 & 0.006 & 0.054 & 0.056 & 0.054 & 0.026 \\
\hline Mean & -0.028 & -0.034 & -0.036 & -0.055 & -0.019 & -0.019 & -0.021 & -0.031 \\
\hline Deviation & 0.007 & 0.010 & 0.015 & 0.030 & 0.005 & 0.005 & 0.007 & 0.015 \\
\hline Skewness & -1.219 & -1.312 & -1.684 & -1.670 & -1.156 & -1.252 & -1.020 & -1.387 \\
\hline Kurtosis & 5.431 & 4.827 & 6.347 & 5.971 & 5.137 & 4.928 & 4.120 & 5.217 \\
\hline Backtesting & 0.003 & 0.002 & 0.002 & 0.369 & 0.777 & 0.549 & 0.396 & 0.000 \\
\hline$E S$ & \multicolumn{4}{|c|}{$1 \%$ significance level } & \multicolumn{4}{|c|}{$5 \%$ significance level } \\
\hline Model & Normal & Skewed $t$ & FHS & EVT & Normal & Skewed $t$ & FHS & EVT \\
\hline Mean & -0.032 & -0.046 & -0.051 & -0.075 & -0.024 & -0.029 & -0.032 & -0.046 \\
\hline Deviation & 0.008 & 0.015 & 0.021 & 0.045 & 0.006 & 0.008 & 0.012 & 0.025 \\
\hline Skewness & -1.238 & -1.256 & -1.444 & -1.834 & -1.199 & -1.306 & -1.339 & -1.636 \\
\hline
\end{tabular}

REAd | Porto Alegre - Edição 82 - N 3 - setembro/dezembro 2015 - p. 648-658 
Sergio Guilherme Schlender, Marcelo Brutti Righi \& Paulo Sergio Ceretta

\begin{tabular}{lllllllll}
\hline Kurtosis & 5.513 & 4.423 & 5.639 & 6.192 & 5.343 & 4.828 & 5.218 & 5.852 \\
\hline Backtesting & 0.005 & 0.112 & 0.452 & 0.589 & 0.007 & 0.214 & 0.386 & 0.508 \\
\hline \multicolumn{7}{c}{ Source: Authors }
\end{tabular}

Subsequently, in order to analyze the estimated risk models in log-returns of the future gold, we present descriptive statistic and backtesting results in Table 2 . We consider $1 \%$ and $5 \%$ significance levels for $\mathrm{VaR}$ and ES measures, with an estimation window of 500 observations. Based on the results in Table 2, the estimation models, except EVT model at 1\% significance level, show more proportion of returns that exceed the predicted VaR (mean), which denote an underestimation of VaR. This underestimation presents a danger for risk estimation in gold investments, once greater losses than the VaR are not considered in these models. Hammoudeh et al. (2011) find, is some level, similar results to these.

All estimation models present negative values for mean, mainly due to the increasing impact of negative extreme values. EVT and FHS models have the most parsimonious estimates, once it exhibits the most negative mean, while Normal and Skewed $t$ models are the less conservative. This pattern is valid for both VaR and ES. In standard deviation, there is more dispersion of estimates in $1 \%$ quantiles of VaR and ES than $5 \%$ quantiles, denoting a turbulent pattern in extreme situations. Further, despite the fact that all estimation models have very volatile prediction, EVT produces the most volatile risk estimates while the Normal and Skewed $t$ show less volatile risk, as pointed out by its standard deviation in all four scenarios. Thus, the EVT model presents a better capturing of negative returns, but more volatile in risk estimation. This bad performance of skewed $t$ is in accord to So et al. (2014), who criticizes asymmetric models, contrary to Chkili et al. (2014), which argues in favor of such approaches.

Regarding the skewness, in general models it tends to exhibit negative symmetry, indicating that risk estimates are likely to concentrate further below their mean, as expected for a turbulent period. For kurtosis, in general models it tends to exhibit a leptokurtic one, which confirms the risk estimation for tail values of the distribution. Thus, aligned with its volatile behavior, EVT does produce too many extreme VaR and ES estimates as the Normal and Skewed $t$ models and FHS, which follow the return dynamics more closely. The exceptional pattern occurs in VaR $1 \%$ significance level.

On the other hand, the backtesting results indicate that Normal, Skewed $t$ and FHS models are the worst models in VaR 1\%, once it rejects the null hypothesis that risk estimated for these models conduct the risk in gold investments, while EVT model is the worst model for VaR 5\%. These situations denote the better performance of Normal, Skewed $t$ and FHS REAd | Porto Alegre - Edição 82 - N 3 - setembro/dezembro 2015 - p. 648-658 
models in VaR when it does not consider the presence of extreme values of gold and the better performance of EVT model when there are these extreme values. In ES scenarios, only Normal model rejected the null hypothesis in $1 \%$ and $5 \%$ significance level. This represents a problem for those who want to use it in risk management, once it underestimate risk and does not present even one correct violation rate.

In summary, the less conservative Normal model, except in VaR 5\%, has the worst results, perhaps because the conditional heteroscedastic effect is not so strong for gold. Further, the most parsimonious EVT performs well for extreme quantiles of $\mathrm{VaR}$, and it is dominant for ES estimation model. In literature, Jang (2007) finds a good performance of EVT in VaR and ES risk estimation if compared with GARCH and RiskMetrics models. We denote that this pattern also occurs in extreme values of gold. Chaithep (2012) presents the importance of EVT model to estimate the VaR post 2008 crisis, but we verify that this model presents violations ( $\mathrm{VaR} 5 \%)$ when it concerns conditional models in this period. Thus, we analyze the ES estimation of these models and observe the outperformance of EVT over GARCH models and FHS model.

\section{CONCLUDING REMARKS}

In this paper, we verify the risk in future gold investments regarding conditional models with distinct distributions, once we consider the presence of negative extreme returns over $\mathrm{VaR}$ and ES risk estimation. Thus, we provide a detailed assessment that allows inferring which model is more precise in a backtesting framework.

We verify that the recent instability of gold prices and the presence of more negative extreme values can difficult the gold protection. Thus, we perform one backtesting framework, where the EVT approach has the most conservative and volatile risk estimates, with satisfactory results, especially in extreme situations. The Normal model, frequently used as a benchmarking for risk management, exhibits a poor performance in most scenarios analyzed.

Following the concern about the performance of risk in gold investments in negative economic conditions and the possible presence of "flight to safety syndrome" of gold demand 
over turbulent periods, we suggest this backtesting framework for future comparative analysis of the performance indices of return of gold with other precious metals.

\section{REFERENCES}

AGYEI-AMPOMAH, S. A. M.; GOUNOPOULOS, D.; MAZOUZ, K. Does gold offer a better protection against sovereign debt crisis than other metals? Journal of Banking and Finance, vol. 40, pp. 507-521, 2014.

BARONE-ADESI, G. VaR without correlations for portfolios of derivative securities. Journal of Futures Markets, vol. 19, n. 5, pp. 583-602, 1999.

CINER, C.; GURDGIEV, C.; LUCEY, B. M. Hedges and safe havens: An examination of stocks, bonds, gold, oil and exchange rates; Int. Rev. Financ. Anal., vol. 29, pp. 202-211, Set. 2013.

CHAITHEP, K. Value at Risk Analysis of Gold Price Returns Using Extreme Value Theory. The Empirical Econometrics and Quantitative Economics Letters, vol. 1, n. 4, pp. 151-168, 2012.

CHKILI, W.; HAMMOUDEH, S.; NGUYEN, D. K. Volatility forecasting and risk management for commodity markets in the presence of asymmetry and long memory, Energy Econ., vol. 41, pp. 1-18, Jan. 2014.

CHRISTOFFERSEN, P. Evaluating interval forecasts. International Economic Review, vol. 39, n. 4, pp. 841-862, 1998.

ELDER, J.; MIAO, H.; RAMCHANDER, S. Impact of macroeconomic news on metal futures. J. Bank. Financ., vol. 36, no. 1, pp. 51-65, Jan. 2012.

GIANNOPOULOS, K.; TUNARU, R. Coherent risk measures under filtered historical simulation. Journal of Banking and Finance, vol. 29, pp. 979-996, 2005.

HAMMOUDEH, S. M.; YUAN, Y.; MCALEER, M.; THOMPSON, M. A. Precious metalsexchange rate volatility transmissions and hedging strategies, Int. Rev. Econ. Financ., vol. 19, n. 4, pp. 633-647, 2010..

HAMMOUDEH, S.; YUAN, Y. Metal volatility in presence of oil and interest rate shocks. Energy Economics, vol. 30, pp. 606-620, 2008.

REAd | Porto Alegre - Edição 82 - Nº 3 - setembro/dezembro 2015 - p. 648-658 
HAMMOUDEH, S.; MALIK, F.; MCALEER, M. Risk management of precious metals. Quarterly Review of Economics and Finance, Vol.51, n.4, pp.435-441, 2011.

HILLIER, D.; FAFF, R.; DRAPER, P. Do precious metals shine? An investment perspective. Financial Analysts Journal, vol. 62, pp. 98-106, 2006.

JANG, J. An Extreme Value Theory Approach for Analyzing the Extreme Risk of the Gold Prices. Journal of Financial Review, vol. 6, pp. 97-109, 2007.

MCNEIL, A.; FREY, R. Estimation of tail-related risk measures for heteroscedastic financial time series: an extreme value approach. Journal of Empirical Finance, vol. 7, pp. 271-300, 2000 .

SO, M. K. P.; CHAN, R. K. S. Bayesian analysis of tail asymmetry based on a threshold extreme value model, Comput. Stat. Data Anal., vol. 71, pp. 568-587, 2014. 